\title{
Synthesis, characterisation, and performance evaluation of tri-armed phenolic antioxidants
}

Article

Accepted Version

Creative Commons: Attribution-Noncommercial-No Derivative Works 4.0

Higgins, C. L., Filip, S. V., Afsar, A. and Hayes, W. (2020)

Synthesis, characterisation, and performance evaluation of triarmed phenolic antioxidants. Tetrahedron Letters, 61 (28). 152127. ISSN 0040-4039 doi:

https://doi.org/10.1016/j.tetlet.2020.152127 Available at https://centaur.reading.ac.uk/91194/

It is advisable to refer to the publisher's version if you intend to cite from the work. See Guidance on citing.

To link to this article DOI: http://dx.doi.org/10.1016/j.tetlet.2020.152127

Publisher: Elsevier

All outputs in CentAUR are protected by Intellectual Property Rights law, including copyright law. Copyright and IPR is retained by the creators or other copyright holders. Terms and conditions for use of this material are defined in the End User Agreement.

www.reading.ac.uk/centaur 
Central Archive at the University of Reading

Reading's research outputs online 


\title{
Synthesis, characterisation, and performance evaluation of tri- armed phenolic antioxidants
}

Clare L. Higgins ${ }^{1}$, Sorin V. Filip ${ }^{2}$, Ashfaq Afsar ${ }^{1}$ and Wayne Hayes ${ }^{1 *}$

${ }^{1}$ Department of Chemistry, University of Reading, Whiteknights, Reading, RG6 6AD, UK.

2 BP Formulated Products Technology, Research \& Innovation, Pangbourne, UK.

* Corresponding author. Tel.: +44118378 6491, Fax: +44 1183786331

Email address:w.c.hayes@reading.ac.uk

\begin{abstract}
:
In this study, a series of core units (glycerol, triethanolamine and triisopropanolamine derivatives) were investigated for their use in tri-armed phenolic antioxidants. The antioxidant ability of these tri-armed phenolic compounds featuring different core units were then evaluated in a hydrocarbon lubricant using differential scanning calorimetry (DSC) and compared to the commercially available antioxidants Irganox L135 and Irganox L57. An impressive oxidation induction time of ca. 9-12 minutes was observed for the glycerol based antioxidants when compared to the commercial antioxidants (ca. 4-6 minutes), whereas in contrast in the case of triethanolamine and triisopropanolamine derived antioxidants, a solubilising unit was incorporated in order to provide appropriate solubility within the hydrocarbon medium and revealed an excellent oxidation induction time of ca.1112 minutes.
\end{abstract}

Keywords: Glycerol, Triethanolamine, Triisopropanolamine, Tri-armed Phenolic Antioxidants, Oxidative Stability Studies

\section{Introduction}

The requirement for enhanced fuel efficiency and lower tailpipe $\mathrm{CO}_{2}$ emissions have led to the introduction of alternative fuels from renewable resources for the partial substitution of conventional petroleum-derived fuels. [1] Biodiesel, which consist of saturated and unsaturated long-chain fatty acid alkyl esters along with glycerol fractions are both products of trans-esterification reactions that can be manufactured from various oil feedstocks; for example, oils from rapeseed, sunflowers, soybean, canola and palm, waste cooking oils and sewage sludge. [2-5] Biodiesel has great potential as an alternative fuel for compression ignition engines because its chemical composition is comparable to diesel fuel but with an 
easy to handle higher boiling point and lower carbonaceous emissions. [6-9] In the light of the increased demand for biodiesel, especially in Europe and the Americas, there is a potential for overproduction of the glycerol by-product. Biodiesel production generates about $10 \%(w / w)$ of crude glycerol and, with the world biodiesel market continuously increasing, it has been predicted that by 2020 more than 4 billion litres of glycerol will be produced per annum. [10] This surplus has prompted the chemical industry to seek application of glycerol as a low-cost feedstock in areas such as fuels, chemicals, the automotive industry, pharmaceuticals and detergents. However, finding new uses for the excess glycerol from biodiesel production is still a major question that needs to be addressed. [11-13] Glycerol has also been used for a number of years as a monomer in the synthesis of dendritic macromolecules targeted for deployment in biological applications such as drug delivery systems and tissue engineering. [14-16] Only a few examples have been reported where glycerol is transformed into radical-trapping fuel additives. [17] Such an application is particularly attractive as it enables the glycerol by-product generated by plants grown for biodiesel production to be used to improve the resistance of this fuel stock to auto-oxidation. The oxidation process of biodiesel can be particularly detrimental because it leads to the formation of hydroperoxides which produces insoluble gums and sediments that can plug fuel filters or make deposits on the fuel injector leading to ineffective engine operation. [18] In addition, the final products of oxidation can also increase the viscosity of the fuel that in turn leads to poor fuel atomization. [18] Another notable class of dendritic macromolecules are poly(amidoamines) (PAMAM) dendrimers and were first reported by Tomalia and co-workers in the 1980s. [19] PAMAM dendrimers are particularly unique because they can be designed to mimic the structural architecture of globular proteins and hence a range of biomedical applications have been proposed for their use such as drug delivery, molecular encapsulation and gene therapy. [20-21] PAMAM dendrimers typically consist of an ethylenediamine core, however, the more flexible triethanolamine core has been recently reported. [22-23] Ottaviani and co-workers [24] reported a series of PAMAM dendrimers with a triethanolamine core which revealed interesting copper (II) binding characteristics. The transition metal binding ability of the triethanolamine core has been known for a number of years [25-27] and could be particularly relevant in the design of oxidation inhibitors as traces of transition metal ions play a significant role in the catalysis of the oxidation processes. [28] It is feasible that the oxidative stability of a material could be enhanced by introducing an antioxidant with both radical scavenging and metal chelation properties. In this paper, we report the synthesis of a series of tri-armed sterically hindered phenolic-based antioxidants whereby glycerol and 
triethanolamine derivatives were utilised as the core unit. Triisopropanolamine was also used as a central core monomer as it was proposed that the methyl moieties of the core would provide additional solubility to the antioxidant. Solubilising alkyl chains were introduced to the core unit to improve dispersion within a hydrocarbon medium. Promisingly, in comparison to the industrial antioxidants Irganox L135 and Irganox L57, these new tri-armed materials exhibited enhanced stabilisation properties when blended into a lubricant base oil and subjected to accelerated oxidative conditions.

\section{Results and Discussion}

\subsection{Synthesis}

Initial synthesis began by exhaustively coupling all three hydroxyl moieties of glycerol $\mathbf{1}$ with 3-(3,5-di-tert-butyl-4-hydroxyphenyl)propionic acid 2, using N,N-dicyclohexylcarbodiimide (DCC) mediated esterification [29-30] to generate the first generation triphenol $\mathbf{3}$ as a yellow oil in $70 \%$ yield (Scheme 1) (see ESI for the spectroscopic data of the compounds described herein). The difference in reactivity of the primary and secondary hydroxyl moieties of $\mathbf{1}$ was then exploited to introduce 2-ethylhexanoic acid $\mathbf{4}$ as a solubilising alkyl chain with the aim to improve dissolution within a hydrocarbon medium. To generate the racemic diphenol $\mathbf{5}$, the primary alcohol moieties of $\mathbf{1}$ were first reacted with two equivalents of $\mathbf{2}$ to generate diester 6 with one free hydroxyl moiety, followed by another DCC mediated esterification of the hydroxyl moiety of 6 with acid $\mathbf{4}$ (Scheme 2).

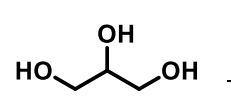

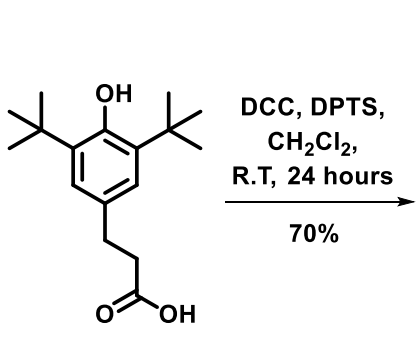

2

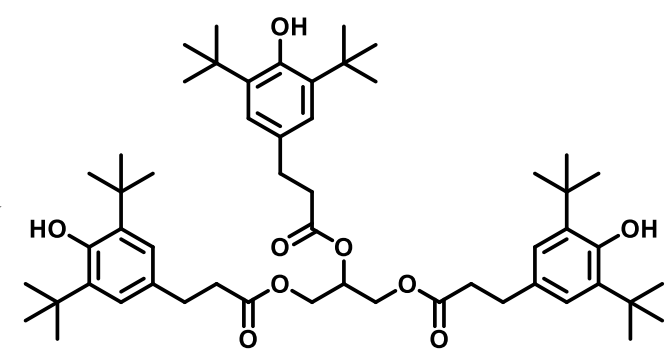

3

Scheme 1. Synthesis of the triphenol 3 from the reaction between glycerol 1 and 3-(3,5-ditert-butyl-4-hydroxyphenyl)propionic acid 2. 

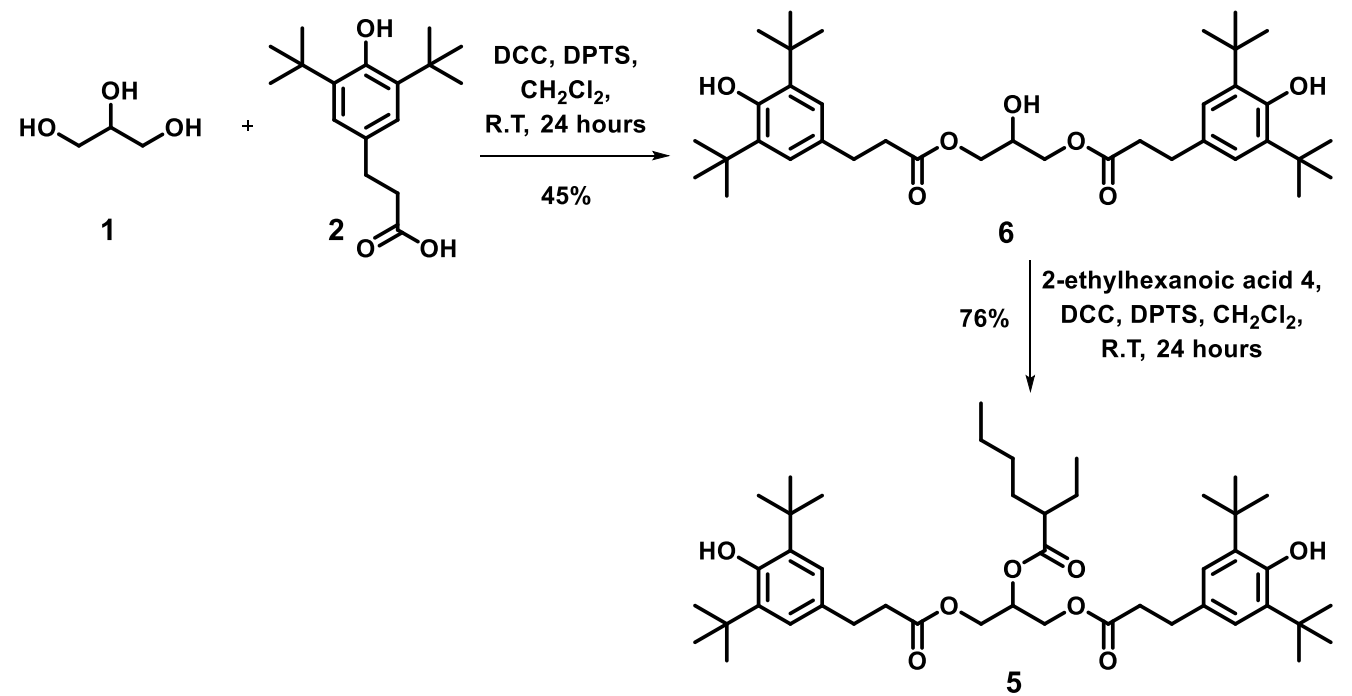

Scheme 2. Synthesis of the diester $\mathbf{6}$, followed by reaction of the remaining secondary hydroxyl to yield the diphenol $\mathbf{5}$.

The final reaction (Scheme 3) of the glycerol series involved incorporation of two alkyl moieties onto the glycerol monomer 1 . In this case, the primary hydroxyl moieties were first reacted with the acid $\mathbf{4}$ to yield the diester $\mathbf{7}$, followed by reaction of the remaining secondary hydroxyl moiety with $\mathbf{2}$ to yield the racemic monophenol $\mathbf{8}$ as a colourless oil in $75 \%$ yield.

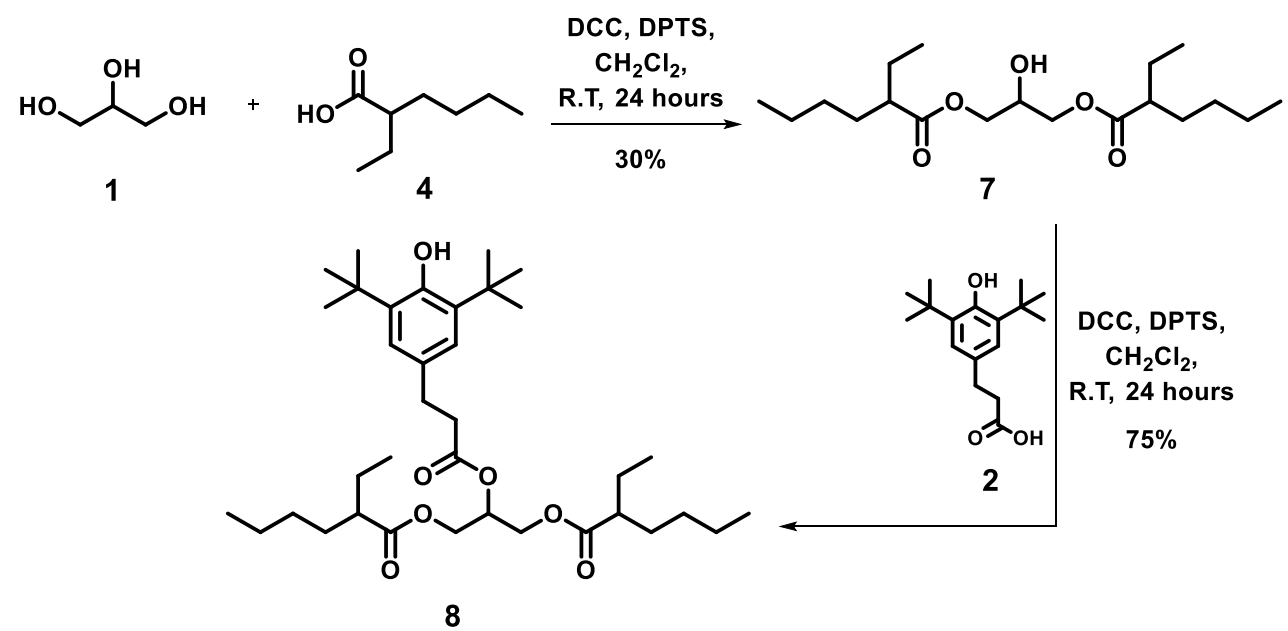

Scheme 3. Synthesis of the diester $\mathbf{7}$ followed by reaction of the remaining secondary hydroxyl moiety to yield the monophenol 8 .

The second series featuring different core units saw the use of triethanolamine 9 and triisopropanolamine $\mathbf{1 0}$ which provided a nitrogen at the core of the macromolecule. Triethanolamine 9 was first reacted with 3-(3,5-di-tert-butyl-4-hydroxyphenyl)propionic acid 2 in a DCC mediated esterification to afford the triphenol $\mathbf{1 1}$ as a waxy solid in $65 \%$ yield (Fig. 
1, Scheme S1). Triisopropanolamine $\mathbf{1 0}$ was also used as the central core unit as it was proposed that the methyl moieties of the core would provide additional stability to both the ester functionalities and the nitrogen core in addition to improving the solubility of the final racemic triphenol 12. The desired tri-armed derivative was achieved successfully via the reaction of triisopropanolamine $\mathbf{1 0}$ with the $\mathbf{2}$ using a DCC mediated coupling reaction (Fig. 1, Scheme S2).
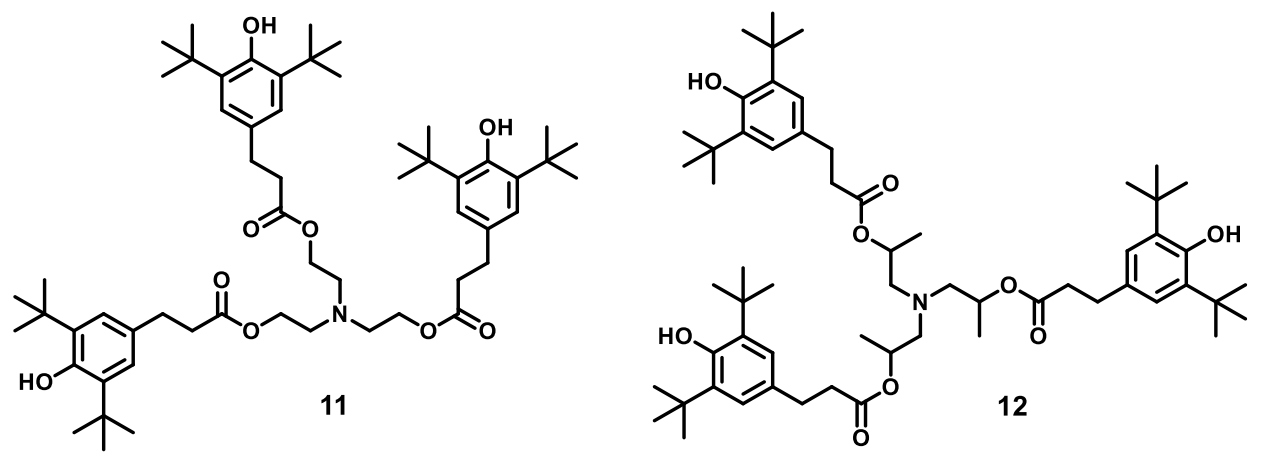

Figure 1. Structures of triphenol $\mathbf{1 1}$ and triphenol $\mathbf{1 2}$ synthesised using the methodology described in Scheme S1 and Scheme S2, respectively.

Although the triethanolamine and triisopropanolamine derivatives 11 and 12 did exhibit excellent antioxidant capabilities, disappointingly their physical properties such as solubility in hydrocarbon media was not yet optimised. Hence, in an attempt to overcome the solubility issues encountered with $\mathbf{1 1}$ and 12, an alternative synthetic approach was targeted to allow incorporation of a solubilising alkyl chain. The synthesis was achieved by reacting diethanolamine 13 with 2-ethylhexyl bromide 14 to afford the diol 15. A DCC mediated esterification was then utilised to couple 3-(3,5-di-tert-butyl-4-hydroxyphenyl)propionic acid 2 to the core to yield the racemic diphenol 16 as a yellow oil in 73\% yield (Fig. 2, Scheme S3). For comparison against 12, the synthesis of intermediate diol 18 was achieved by first reacting 1,1'-azanediylbis(propan-2-ol) $\mathbf{1 7}$ with $\mathbf{1 4}$ followed by functionalisation of $\mathbf{1 8}$ with a solubilising alkyl chain 2-ethylhexyl bromide 14 and 3-(3,5-di-tert-butyl-4hydroxyphenyl)propionic acid 2 to afford the racemic diphenol 19 as a yellow oil in $62 \%$ yield (Fig. 2, Scheme S4). 

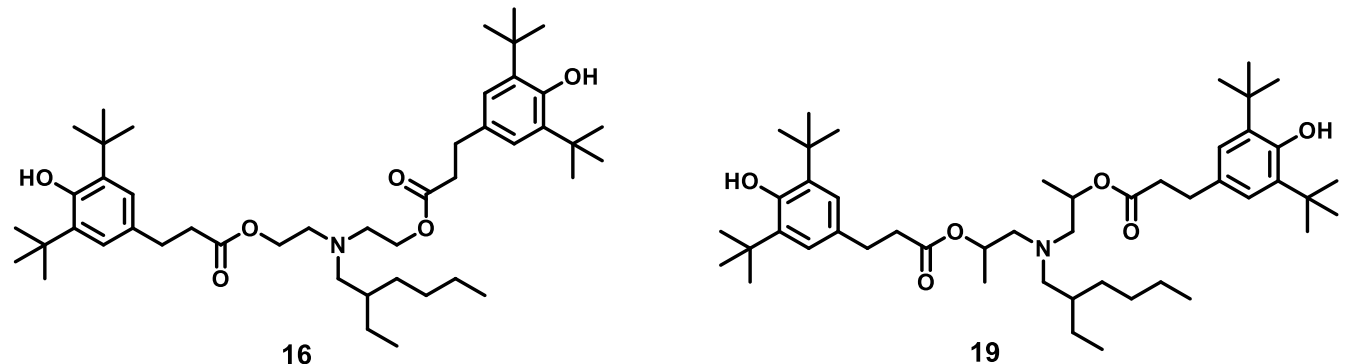

Figure 2. Structures of diisopropanolamine 16 and diphenol 19 synthesised using the methodology described in Scheme S3 and Scheme S4, respectively.

\subsection{Oxidative stability studies}

To assess the antioxidant potential, mono-, di- and tri-phenol glycerol derivatives 3, 5 and $\mathbf{8}$ were blended into a synthetic lubricant base oil - Durasyn ${ }^{\circledR} 164$ (a polyalphaolefin, hydrogenated hydrocarbon base oil composed of dec-1-ene trimers typically used in lubricating oils). Typical lubricant commercial antioxidants Irganox L135 (phenolic antioxidant) and Irganox L57 (aromatic amine antioxidant) were used as a direct comparison and samples were prepared by blending of $0.5 \% \mathrm{w} / \mathrm{w}$ of each antioxidant in $50 \mathrm{~mL}$ of the lubricant base oil. The blends were analysed using pressurised differential scanning calorimetry (PDSC) to monitor the heat effects associated with phase transitions and chemical reactions as a function of temperature. Oxidation induction time (OIT) and oxidation onset temperature (OOT) were used to investigate the effect of antioxidants on the stability of an oil sample. OIT revealed that the presence of glycerol derivatives $\mathbf{3}, \mathbf{5}$ and $\mathbf{8}$ in the base oil had resulted in a significant increase in the stability of the sample as shown in Fig. 3. 


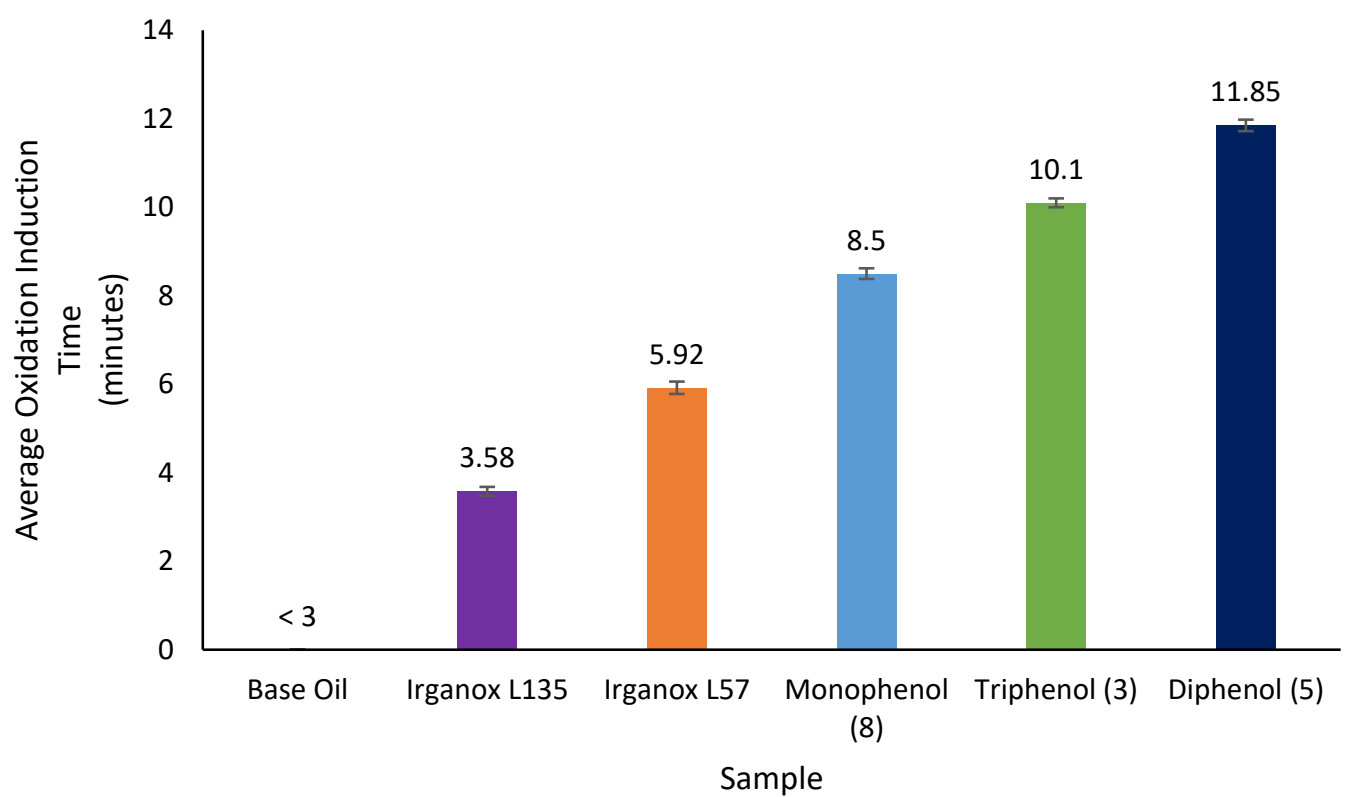

Figure 3. Average oxidation induction time analysis of the glycerol series $\mathbf{3}, 5$ and 8 (tested in duplicate).

The induction time was increased from $<3$ minutes for the unblended base oil to $\mathrm{ca}$. 1012 minutes for the blended samples. In addition, the glycerol derivatives 3, 5 and $\mathbf{8}$ exhibited superior performance to both commercial antioxidants, Irganox L135 and Irganox L57. The OOT results for each oil blend are presented in Fig. 4 where again, a significant increase in temperature was observed when $\mathbf{3}, \mathbf{5}$ and $\mathbf{8}$ were incorporated into the blend when compared to the base oil in isolation (ca. $245-249^{\circ} \mathrm{C}$ ).

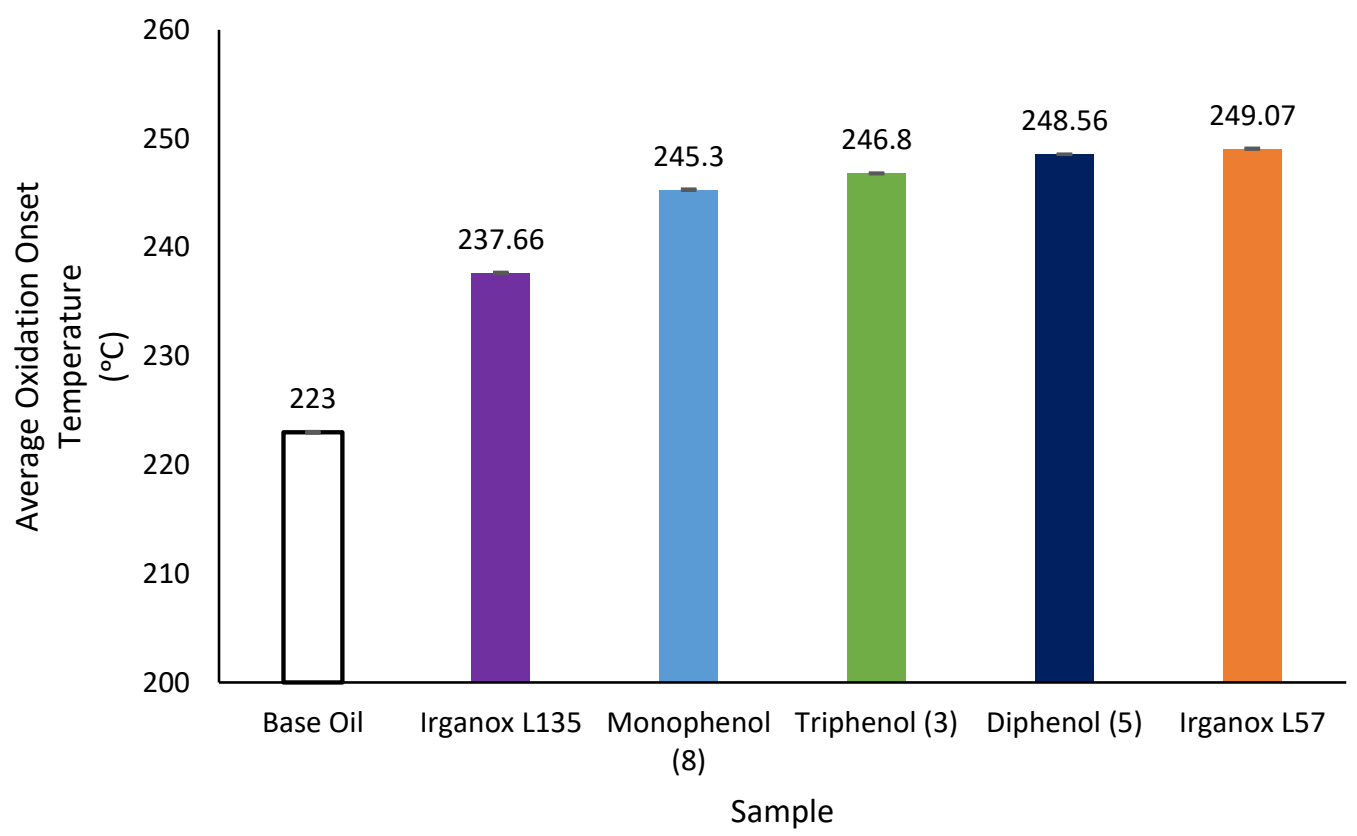

Figure 4. Average oxidation onset temperature analysis of the glycerol series $\mathbf{3}, \mathbf{5}$ and $\mathbf{8}$ (tested in duplicate). 
The structure-activity relationships were also investigated by comparing the triphenol $\mathbf{3}$ and the diphenol 5. It was expected that the triphenol $\mathbf{3}$ would provide the greatest oxidative stability to the lubricant base oil in comparison to the diphenol $\mathbf{5}$ as a result of the extra active phenolic functionality. This, however, was not observed and instead the diphenol $\mathbf{5}$ provided excellent stability with an oxidation induction time of ca. 12 minutes in comparison to $\mathrm{ca}$. 10 minutes for the triphenol 3. This induction time was also much greater than both of the commercially available antioxidants Irganox L135 and L57 and it was proposed that the diphenol $\mathbf{5}$ had the most effective balance between active functionalities and solubility. Oxidative stability analysis of triethanolamine and triisopropanolamine derivatives 11 and 12 proved more challenging as the solubility in the lubricant base oil remained an issue and a longer heating time (ca. 2 hours compared to 30 minutes) and higher temperature ( $\mathrm{ca} .70^{\circ} \mathrm{C}$ compared to $50{ }^{\circ} \mathrm{C}$ ) was required in order to produce the blend. However, unexpectedly excellent OIT of ca. 11-14 minutes and OOT of ca. $245-251^{\circ} \mathrm{C}$ were observed for $\mathbf{1 1}$ and 12 revealing enhanced oxidative stability in comparison to Irganox L135 and Irganox L57 (Fig. $5)$.

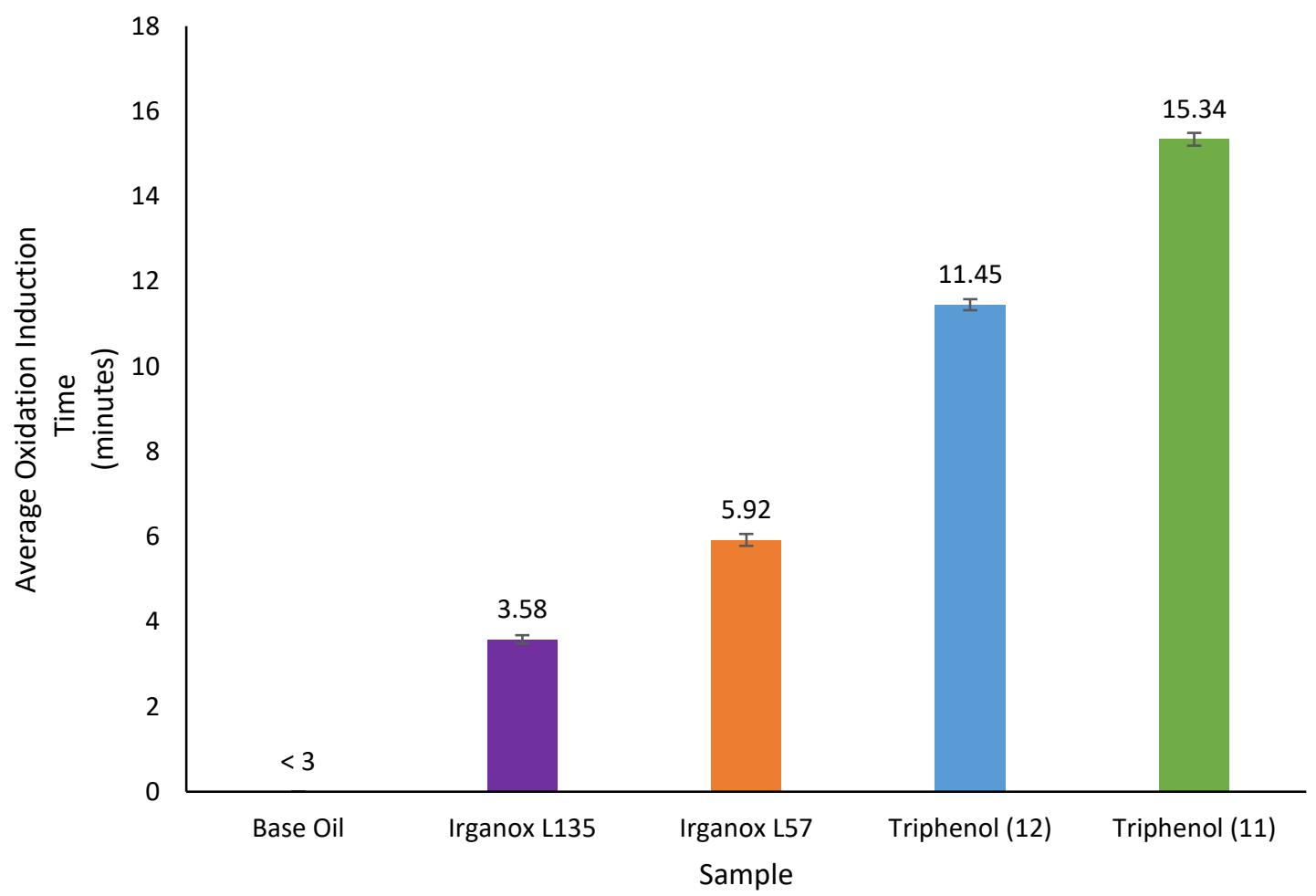

Figure 5. Average oxidation induction time analysis of triphenols $\mathbf{1 1}$ and $\mathbf{1 2}$ (tested in duplicate). 
The above results revealed that these compounds did have very promising antioxidant capabilities but disappointingly solubility was an issue. To further refine the structure of triethanolamine and triisopropanolamine derivatives 11 and 12, an additional alkyl chain was incorporated for enhanced solubility. Oxidative stability analysis of $\mathbf{1 6}$ and $\mathbf{1 9}$ were then carried out that revealed an oxidation induction time of ca. 11-12 minutes and oxidation onset temperature of ca. $245-249{ }^{\circ} \mathrm{C}$ (Fig. 6), performing in the same region as triethanolamine (11), triisopropanolamine (12) and glycerol $(3,5$ and 8$)$ derivatives.

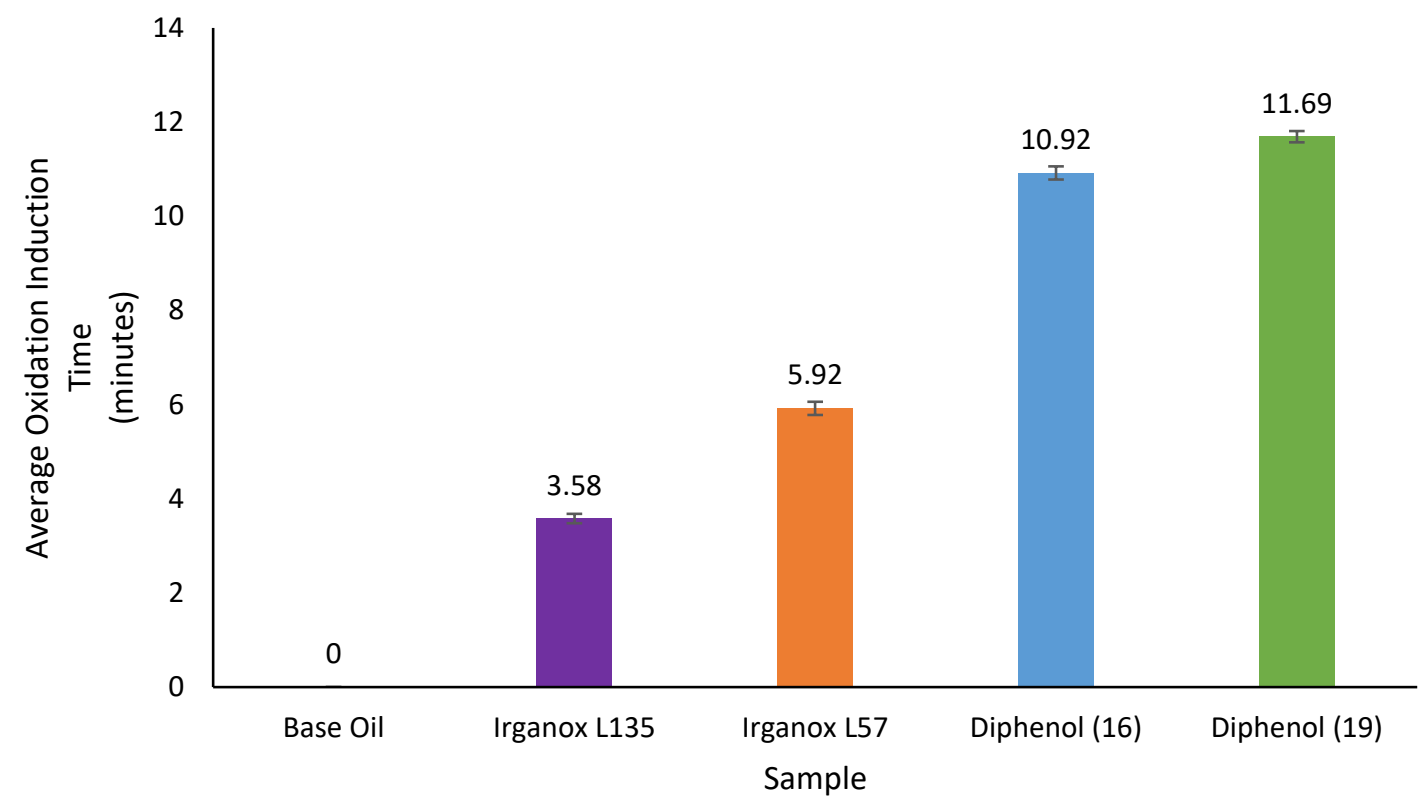

Figure 6. Average oxidation induction time analysis of diphenols $\mathbf{1 6}$ and $\mathbf{1 9}$ (tested in duplicate).

These results highlight the importance of balancing functionality with solubility where replacement of one active phenolic moiety for a single solubilising alkyl chain had little to no effect on the OIT and OOT parameters. In addition, whilst the core monomers themselves do not necessarily contribute to the antioxidant capabilities of these compounds, they do afford higher molecular weight additives which possess a larger number of antioxidant units that are in turn are less volatile (cf. commercially available antioxidants) and thus residence times within the hydrocarbon lubricant matrix are enhanced.

\section{Conclusion}

In summary, a series of alternative core units (glycerol, triethanolamine and triisopropanolamine derivatives) were investigated for their use in the synthesis of tri-armed 
phenolic antioxidants. Oxidation induction time (OIT) revealed that the presence of glycerol based derivatives 3,5 and $\mathbf{8}$ in the base oil resulted in a significant increase in the stability of the sample from < 3 minutes for the unblended base oil to ca. 9-12 minutes for the blended samples. In addition, 3, 5 and $\mathbf{8}$ showed superior performance to both commercial antioxidants, Irganox L135 and Irganox L57. A series of nitrogen core units were also investigated and the triethanolamine and triisopropanolamine derivatives 11 and 12 revealed excellent oxidation induction times of ca.11-14 minutes, however, solubility in the lubricious base oil proved to be an issue. As an alternative, 16 and 19 were synthesised that incorporated a solubilising alkyl chain and revealed oxidation times in the region of ca.11-12 minutes. These results confirmed that the central core unit does not necessarily contribute to the antioxidant capabilities and the solubility of an additive is just as important as antioxidant functionality when considering the design of new tri-armed antioxidants.

\section{Acknowledgements}

The authors acknowledge the UK Biotechnology and Biological Sciences Research Council (BBSRC) and BP p.I.c. for financial support. Use of the Chemical Analysis Facility (CAF) at the University of Reading and Analytical department at the BP Technology Centre, Pangbourne are gratefully acknowledged.

\section{References}

1. G. Karavalakis and S. Stournas, Energy Fuels, 2010, 24, 3682-3686.

2. M. Jerzykiewicz, I. Cwielag and W. Jerzykiewicz, J. Chem. Technol. Biotechnol., 2009, 84, 1196-1201.

3. J. R. Dodson, T. Avellar, J. Athayde and C. J. A. Mota, Pure Appl. Chem., 2014, 86, 905-911.

4. G. Knothe, Fuel Process. Technol., 2005, 86, 1059-1070.

5. P. Lv, Y. Cheng, L. Yang, Z. Yuan, H. Li, W. Luo, Fuel Process. Technol., 2013, 110, 61-64.

6. K. Ryu, J. Mech. Sci. Technol., 2009, 23, 3105-3113.

7. A. S. Ramadhas, A. Muraleedharan and S. Jayaraj, Renew. Energy, 2005, 30, 17891800.

8. G. Knothe, Fuel Process. Technol., 2005, 86, 1059-1070.

9. N. Usta, Energy Convers. Manag., 2005, 46, 2373-2386. 
10. S. Nomanbhay, R. Hussein and M. Y. Ong, Green Chem. Lett. Rev., 2018, 11, 135157.

11. M. Pagliaro, R. Ciriminna, H. Kimura, M. Rossi and C. Della Pina, Angew. Chem. Int. Ed., 2007, 46, 4434-4440.

12. A. Behr, J. Eilting, K. Irawadi, J. Leschinski and F. Lindner, Green Chem., 2008, 10, 13-30.

13. Y. Gu, A. Azzouzi, Y. Pouilloux, F. Jerome and J. Barrault, Green Chem., 2008, 10, 164-167.

14. R. Haag and F. Vogtle, Angew. Chem. Int. Ed. Engl., 2004, 43, 272-273.

15. H. Frey and R. Haag, Rev. Mol. Biotechnol., 2002, 90, 257-267.

16. M. M. K. Boysen, K. Elsner, O. Sperling and T. K. Lindhorst, European J. Org. Chem., 2003, 2003, 4376-4386.

17. Z. Namazifar, F. Saadati and A. A. Miranbeigi, New J. Chem., 2019, 43, 10038-10044.

18. K. Varatharajan and D. S. Pushparani, Renew. Sust. Energ. Rev., 2018, 82, 20172028.

19. D. A. Tomalia, H. Baker, J. Dewald, M. Hall, G. Kallos, S. Martin, J. Roeck, J. Ryder and P. Smith, Polym. J., 1985, 17, 117-132.

20. D. A. Tomalia, Mater. Today, 2005, 8, 34-46.

21. A. W. Bosman, H. M. Janssen and E. W. Meijer, Chem. Rev., 1999, 99, 1665-1688.

22. J. Wu, J. Zhou, F. Qu, P. Bao, Y. Zhang and L. Peng, Chem. Commun., 2005, 2005, 313-315.

23. X. Liu, J. Wu, M. Yammine, J. Zhou, P. Posocco, S. Viel, C. Liu, F. Ziarelli, M. Fermeglia, S. Pricl, G. Victorero, C. Nguyen, P. Erbacher, J.-P. Behr and L. Peng, Bioconjug. Chem., 2011, 22, 2461-2473.

24. M. F. Ottaviani, M. Changiotti, A. Fattori, C. Coppola, P. Posocco, E. Laurini, X. Liu, C. Liu, M. Fermeglia, L. Peng and S. Pricl, Phys. Chem. Chem. Phys., 2014, 16, 685694.

25. K. H. Whitmire, J. C. Hutchison, A. Gardberg and C. Edwards, Inorganica Chim. Acta, 1999, 294, 153-162.

26. A. Karadag, V. T. Yilmaz and C. Thoene, Polyhedron, 2001, 20, 635-641.

27. B. Sen and R. L. Dotson, J. Inorg. Nucl. Chem., 1970, 32, 2707-2716.

28. T. Colclough, Ind. Eng. Chem. Res., 1987, 26, 1888 -1895.

29. B. Neises, W. Steglich, Angew. Chem. Int. Ed., 1978, 17, 522-524. 
30. C. L. Higgins, S. V. Fillip, A. Afsar, W. Hayes, React. Funct. Polym., 2019, 142, 119127. 